\title{
Configuration lifecycle management maturity model
}

\author{
Myrodia, Anna; Randrup, Thomas; Hvam, Lars
}

Published in:

Computers in Industry

Link to article, DOI:

10.1016/j.compind.2018.12.006

Publication date:

2019

Document Version

Peer reviewed version

Link back to DTU Orbit

Citation (APA):

Myrodia, A., Randrup, T., \& Hvam, L. (2019). Configuration lifecycle management maturity model. Computers in Industry, 106, 30-47. https://doi.org/10.1016/j.compind.2018.12.006

\section{General rights}

Copyright and moral rights for the publications made accessible in the public portal are retained by the authors and/or other copyright owners and it is a condition of accessing publications that users recognise and abide by the legal requirements associated with these rights.

- Users may download and print one copy of any publication from the public portal for the purpose of private study or research.

- You may not further distribute the material or use it for any profit-making activity or commercial gain

- You may freely distribute the URL identifying the publication in the public portal

If you believe that this document breaches copyright please contact us providing details, and we will remove access to the work immediately and investigate your claim 


\section{Configuration lifecycle management maturity model}

Highlights:

- Configuration lifecycle management (CLM) describes a configuration model that covers all product life cycles.

- CLM supports the configuration of a product across all life cycle phases.

- CLM facilitates the horizontal and vertical integration of business units and processes.

- CLM integrates and shares configuration knowledge across and beyond an organization.

- A CLM maturity model is proposed for monitoring and evaluating the progress of CLM implementation.

Computers in Industry 106 (2019) 30-47

https://doi.org/10.1016/j.compind.2018.12.006 


\title{
Configuration Lifecycle Management Maturity Model
}

\author{
Anna Myrodia ${ }^{\text {a,b, }}$, Thomas Randrup a , Lars Hvam ${ }^{b}$ \\ a Configit, Midtermolen, 3, 2100, Copenhagen, Denmark \\ b Engineering Management, Technical University of Denmark, Produktionstorvet, Building 424, 2800, \\ Kgs, Lyngby, Denmark
}

\begin{abstract}
Configuration lifecycle management (CLM) encompasses all configuration models across a product's life cycle. CLM covers manufacturers' needs for complex configurable products, which tend to require more seamless integration of all their business units and external stakeholders in terms of process continuity and data exchange. CLM differs from existing life cycle management tools because it focuses on sharing the configuration knowledge and data of a configurable product throughout its entire life cycle across all the involved business units of an organization. Therefore, assessing the maturity level of the organization is important for more effective and efficient implementation of CLM. Based on this, the contribution of this research is the development of a CLM maturity model that serves as a guide for the transition to complete horizontal and vertical integration of CLM knowledge and tools across and beyond an organization. The proposed maturity model is validated against the literature and existing maturity models, in addition to being examined through a workshop with industry representatives and empirical cases.
\end{abstract}

Keywords: configuration life cycle management, product life cycle, maturity model, product configuration, configuration management, case study

\section{Introduction}

One of the unresolved challenges in manufacturing today is the lack of systematic management of manufacturing information that can cover product modeling and related activities in the different life cycle phases of complex configurable products [1]. During a product's life cycle, several configuration models can be developed to generate related product and production specifications, for example, bill of materials (BOM), drawings, and lists of operations during each life cycle phase [2]. At the same time, the amount and diversity of product related information are greatly increased because of product and process complexity and multidisciplinary work [3], making data management beyond human capability, causing difficulties and complexity in product configuration [4]. This challenge is addressed by the configuration life cycle management (CLM) concept, which is defined as the management of a coordinated set of configuration models used for configuring product and product-related specifications in the different phases of a product's life cycle.

CLM is particularly relevant for complex configure-to-order and assembly-to-order products with long life cycles, for example, cars, which include thousands of predefined components, have life cycles more than 10 years, and are vulnerable to change [5]. Hence, the need for a systematic way to control products and product-related information throughout the entire life cycle is imperative $[6,7]$. In the current research, we introduce CLM because we merely address product configuration-related information and focus on complex configurable products, for example, industrial machinery, automobiles, and plants.

To the best of our knowledge, the concept of CLM is new and is emerging from the needs of the industry. Therefore, a systematic approach that facilitates and evaluates this transition and adaptation 
to a CLM concept is needed. Maturity models (MMs) can serve this purpose by providing an overview of and monitoring progress in a specific area [8]. The reason for developing a CLM-MM is that the implementation of the CLM concept requires changes in the processes, systems, and capabilities of individuals from the strategic to execution level [7,9]. However, a need remains on how to assess if a company is prepared for applying a CLM solution. The literature discusses MMs for software in general, but no studied could be found that assess the maturity of a CLM system. This raises the following research question:

What are the levels in a maturity model for a CLM system?

The CLM-MM differs from the general maturity model that is used for configuration management (CM) [10] because the proposed model focuses on product configuration across the entire value chain, aiming for the internal and external integration of systems, processes, and data. The CLM-MM also differs from the suggested MMs for product life cycle management (PLM) implementation [11] because the CLM-MM focuses merely on the configuration process. The MM should cover all the requirements of the configuration-related activities performed and scalability in terms of internal (cross-organizational) and external integration (with suppliers, vendors, customers, etc.) [1]. In terms of practical contribution, the current research aims at developing a structured approach for practitioners that can serve as a tool identifying their current state, helping practitioners decide on future improvements efficiently and methodically.

The remainder of the present paper is structured as follows: First, the basic concepts and CLM are explained, and the relevant literature about CLM is discussed. Second, the research method is explained, which includes an analysis of existing MMs and the development of a MM for assessing CLM maturity by using a design science research (DSR) process [12] and the four-step approach for MM development [13]. Then, the theoretical and empirical validation of the MM is discussed. For theoretical validation, the proposed CLM-MM is compared with existing models and the literature. For empirical validation, a workshop is conducted with experts in the field. The design, activities, and results from the workshop are presented and analyzed. Additionally, a case study is provided, including three companies that are used to test the robustness of the CLM-MM. Finally, overall conclusions regarding this research and further studies are presented.

\subsection{Definition of basic concepts}

To allow for a better understanding of CLM, the basic related concepts around CLM need to be defined. Configuration as a task is defined as the product designing problem when using a predefined set of components and the restrictions on how these components can be combined [14]. The configuration task is solved by using product configuration systems, which are software-based expert systems focusing on both creating product specifications [15], such as design parameters, structural relationships, list of operations, routing plans, quotations and costs [4,16-18], and managing the configuration knowledge [19]. The relevant domain experts have extended knowledge and expertise on the product's life cycle phases; therefore, they are responsible for providing this product knowledge as an input to develop a product model representing their specific life cycle phase [15].

Configuration models are the basis of a product configuration system, serving as a repository of structural, functional, and life cycle information used for generating the product specifications and BOMs [20], which describe the structure of a product and define the number of different types of parts in a configured product [21]. The configuration models include product knowledge for deriving the engineering BOM, sales BOM, manufacturing BOM, service BOM, and so forth [6]. The product modeling process is subjective to the expert providing the knowledge input, which might lead to 
inadequate product configuration models [22]. Hence, the input for developing and validating a CLM model should be provided by several experts from both the commercial and technical perspectives of the product [23].

\subsection{Description and relevance of the CLM concept}

CLM can be seen in two ways: the functional view (Fig. 1) and the systems view (Fig. 2). The functional view describes the configuration model that includes all the required information to configure a product across all life cycle phases, for example, product attributes and rules. In this research, for consistency, we describe the product's life cycle in (from inception to disposal [24]) four phases, as follows: engineering, sales, manufacturing, and service. The engineering phase includes designing, prototyping, and verifying the product and its specifications. The sales phase covers the sales process, along with marketing, market requirements, and pricing. The manufacturing phase covers the production process and sourcing, assembling, and order fulfilling. Finally, the service phase describes installation, maintenance, upgrades, decommissioning, and final disposal. The modeling activity is located in the middle because this is where the product configuration model is developed by including the input from all the different phases and utilizing its output in a similar way.

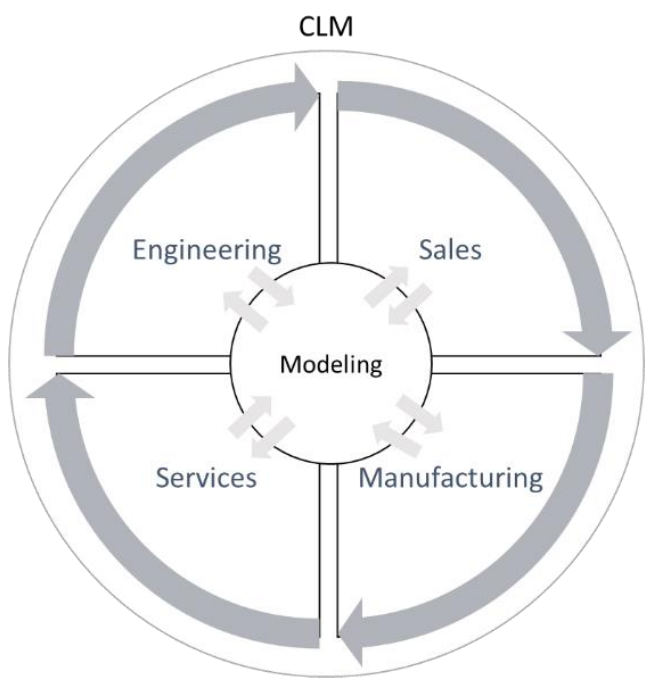

Fig. 1. Functional view of CLM (adapted from [5]).

The systems view describes the integration of CLM with other information technology (IT) systems in a company. CLM is at the center and is connected to other data repositories, hence allowing for configuration-related information to be both utilized from multiple operational sources and shared to support decision making at the different life cycle phases of a configurable product [7]. The data required to configure a product and generate its specifications across all life cycle phases are stored in several systems, such as PLM, customer relationship management (CRM), enterprise resource planning (ERP), Excel files, Word documents, PDF files, and so forth because these data are considered to be necessary for manufacturing companies to maintain their competitive advantage [24]. The input for their product configurators comes from different sources and experts because the knowledge required for developing the product models is kept in other systems [15]. Therefore, the CLM system needs to exchange information with these systems to be functional and stay up-to-date. In other words, CLM receives data inputs from the surrounding IT systems and uses these data in the configuration model. The configuration process takes place within the configurators in CLM, and then, the generated product specifications are exported to all the surrounding systems. Therefore, CLM is placed in the center of Fig. 2. 


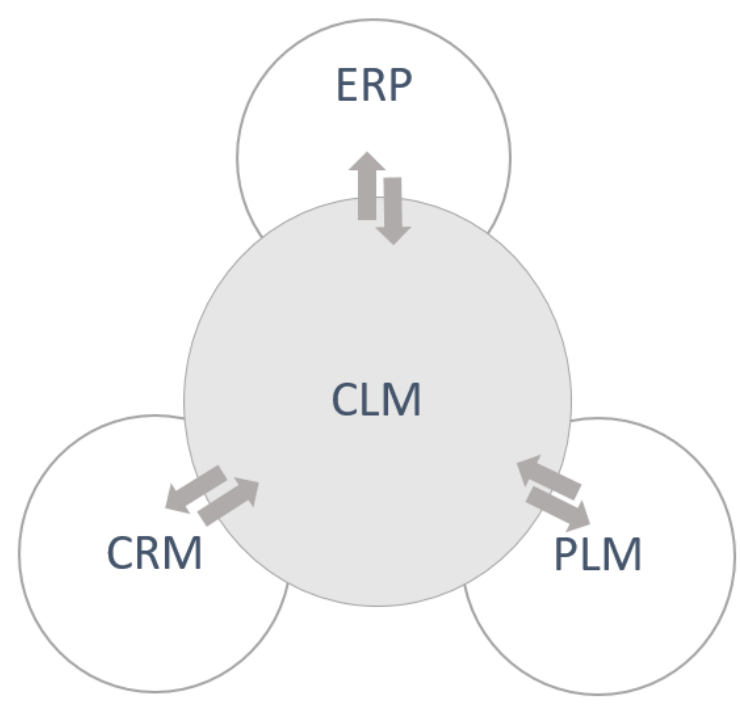

Fig. 2. Systems view of CLM (adapted from [5])

By combining the aspects from the functional and systems views, CLM addresses the issue of integration across the life cycle phases [25], including internal (business units and geographic locations) and external (suppliers, distributors, and customers) stakeholders.

To better understand CLM and demonstrate its practical implications, consider the following simplified example: Company $\mathrm{X}$ uses product configurators to model and engineer their complex configurable products. The engineering rules are provided as inputs to the configurator from the PLM system. Then, the company uses a configure-price-quote (CPQ) solution for the sales process. CPQ software are used in the sales process, and they include information regarding how the product is configured and how the price is determined; based on this, the software generate the quotation document [20]. All data required for the different markets and customers are provided by the CRM system, and pricing rules are provided by the ERP system. The sales personnel use the CPQ solution to configure the products based on customers' specifications; the sales personnel can also place orders and create quotations for the customers. After an order has been placed, the relevant information about the customer is stored in the CRM system, and all the relevant information about the products ordered is stored in the PLM system. For example, BOMs are sent from the PLM system to the ERP system and forwarded to the manufacturing department to start production. When a sold product requires service or replacement, the service department needs to access and identify the valid configuration of the product and its parts that need maintenance and then relate the products to the newest version available. To do so, all the historic changes in each configurable product sold must be tracked to identify the right version of the specifications.

The above example describes a challenging situation that all companies face when several configuration and IT systems are in place and there is a need to exchange data across the different life cycle phases of a configurable product. This challenge is also described as the extension of configuration ontology to include both the product knowledge related to all life cycle phases of a product and to share commonality across companies [26]. Moreover, recent research indicates that there is a need for additional focus on how the support tools that control the information flow among distributed manufacturing units behave coherently under time, budget, manufacturing, and environmental constraints [27]. Software that can support CLM is being developed and increasingly applied in industry; for example, manufacturers envision being able to connect PLM systems with 
manufacturing and supply chain data and processes [28]. CLM addresses all these dimensions (IT systems, business processes, and a product's life cycle phases) and serves as a complete solution for managing a coordinated set of configuration models and their related information.

CLM differs from existing life cycle management and data management concepts, such as PLM, ERP, CRM, and product data management (PDM), in that CLM covers all configuration models and the generation of specifications for products across all life cycle phases. Here, different concepts and tools support the management of data, knowledge, and configurations in discrete life cycle phases [29]. PDM focuses on design and engineering data, and PLM originates from PDM but covers the entire life cycle of a product [30]. Enterprise integration engineering also builds on this concept and describes how to improve engineering processes by using IT-and in particular PLM tools - to create a complete representation of an enterprise [31]. However, CLM differs because it describes all configuration models for configuring products and product-related specifications in the different phases of a product's life cycle.

Furthermore, CLM differs from an ERP system because of the limited configuration functionality of the latter. As discussed by Zhang et al. [32], major ERP systems have a configuration module embedded within them; yet they deal either with sales configuration or the configuration of manufacturing specifications without considering the remaining life cycle phases of a configurable product [33].

In a similar way, the configuration capabilities distinguish a PLM from a CLM system. Although PLM systems offer some configuration functions, they are limited and cannot cover the evolution of PDM in the long term because of the increasing complexity of the products, the number of users, and the amount of data [34]. PLM systems include functionalities that support product data creation, such as the structure of the product and management of the product data generated from other systems, such as CAD models [35]. Furthermore, within PLM systems, technical data are organized within "configurations," in other words, within predefined groups [34]. The main differentiator between PLM and CLM systems is that PLM focuses on keeping track of the existing product information and process information, for example, product specifications [36]; however, CLM focuses on maintaining the configuration model for generating new specifications from the configuration system. Knowledge management methods and tools are required to support a PLM system, and CM is an integral part of PLM systems [34,37]. PLM and CLM can work together; PLM focuses on integrating life cycle information and the knowledge supported by computer-aided engineering technologies (CAD, CAM, and $\mathrm{CAE}$ ) and knowledge-based engineering systems (KBESs) [31]. CLM is one of these KBESs focusing on the generation and management of configuration product models. The product model in a PLM system consists of either numerous static product representations or a multimodel that is associated with different views (e.g., design, production, and maintenance), and its primary focus is to manage product development and support its life cycle [38]. However, these PLM models evolve independently; therefore, coherence, maintenance, and information sharing remain a challenge and cannot be ensured [37]. CLM fills in this gap by consistently and coherently describing all configuration models.

The use of life cycle management or data management systems are not a prerequisite for the implementation of the CLM concept. However, in the example above, we mention different IT systems and processes to address the challenge of the alignment and coordination of the product-related information across all life cycle phases of complex configurable products.

\section{Literature Review}

\subsection{Literature review related to CLM}


In this section, the main literature is examined and discussed. In the literature search, when the search term was "configuration life cycle management," only one article was found [5]. Therefore, the rest of the studies found centered on CM and PLM. The literature review here focuses on these two main concepts with the aim of identifying the gap in the relevant research of CLM within an organization.

In line with the description in the introduction, $\mathrm{CM}$ applies technical and administrative tools to the development, engineering, sales, production, and other life cycles of a configured product [39]. In other words, CM controls the design, sales, manufacture, and after-sales service of a product [40]. According to the Institute of Configuration Management [41], CM is the process that manages products, facilities, and operations in the form of requirements, ensuring consistency of the results with these requirements. However, with advances in technology, this description of CM was revised to address the integration of all core business processes. The following description is closer to CLM: having a common platform for managing configuration models throughout all the life cycle phases of a product across the core organization and across its external stakeholders (e.g., vendors, suppliers, and distributors); this common platform leads to improved flexibility and efficiency, along with the elimination of redundancy by having IT systems - particularly configurators-integrated into common platforms, connecting suppliers, producers, distributors, and customers [42,43].

The management of a product from inception to disposal is of great strategic importance [44], especially in today's networked economy, where partnering with external stakeholders, such as suppliers and codevelopers, is increasing. This collaboration is possible because of advances in IT technology and the utilization of IT systems in organizations that allow for this exchange of information [45]. This is also supported by the fact that the horizontal and vertical integration of systems is one of the nine technologies that are transforming the future of industrial production [46].

Therefore, companies are keen to move from the functional fragmentation of $\mathrm{CM}$ to an organizational structure in which the $\mathrm{CM}$ activities and requirements are handled across the product's life cycle [40]. Based on a survey presented in the CM benchmark report [47], the main processes in which product data are covered by configurators are product documentation, manufacturing, and quality specifications. Based on the results of this survey and analysis of the current state of the CM practices, several suggestions are made, focusing on extending this coverage by starting early in the conceptual design phase. This is also recommended by other researchers, who stress that the earlier the configuration process starts in the life cycle, the higher the advances from the achieved benefits will be $[48,49]$.

One dimension of CLM focuses on all life cycle phases to ensure the coherency, consistency, and validity of all the data and subsequent configurations [50]. Better data acquisition, traceability, and reusability starting from design activities to production and after-sales services is a way of reducing process time and cost $[20,51]$. This can be achieved by centralizing the data management and offering different views of the product data based on the relevant roles; by targeting process standardization, management of the configuration models in each process can be promoted and further improved [47]. This is aligned with the collaborative working contexts, where the knowledge encapsulated within expert models is used across the organization for different life cycle phases [51].

As simple and obvious as this solution may sound, developing, integrating, and aligning configurations across all life cycle phases can be challenging. Two phases alone, for instance, aligning decisions between configuring and producing the product, have received a lot of attention from researchers [32,52-54]. The challenge of aligning these two phases lies in the individual constraints and their consequences. A suggested solution for overcoming this issue is to consider these activities concurrently $[55,56]$. Similarly, when considering the alignment of all life cycle phases, the solution 
should follow the same logic and consider all the configuration activities in an overall concurrent approach. Therefore, a master system that records the configuration logic and the individual configurations is needed [5].

However, apart from integrating IT systems across the organization and creating standardized processes, communicating the change is also very important for achieving a successful culture of CM. Support from upper management, close collaboration, enhanced training and knowledge-sharing activities, and overall engagement from all organizational levels are courses of action for overcoming resistance to CLM change $[15,19,57,58]$.

Another crucial factor when discussing CLM is the feasibility analysis of a CLM system. Investing in several enterprise information systems, such as ERP, CRM, and product configuration systems, is a decision based not only on the needs of an organization and the targeted benefits, but also on the cost of implementation and maintenance, time spent, and return on investment $[59,60]$.

In conclusion, the literature addresses the issue of handling configuration models that have a common systematic approach. However, in reality, this systematic approach to handling configuration-related activities and knowledge across life cycle phases does not exist. Therefore, there is a need to have a wider focus on the subject and measure its maturity among other business processes already in place [61].

\subsection{Literature review of existing $M M s$}

MMs have been widely used for assessing and evaluating the level of an organization in managing a specific process. MMs are not used for general management; each model focuses on a specific area [8]. Therefore, different well-known MMs address the management of business processes [62], capabilities and integration of capabilities [63], information process [64], knowledge [65], information quality [66], IT enterprise [67], service-oriented architecture [68], strategy and alignment [69], design automation [13], and product life cycle [11]. These MMs were considered when the CLM-MM was developed because of their relevance to the area covered by CLM. One article that described a CMMM was identified, but it is very domain specific for scientific facilities [70]. Willner et al. [13] conduct a literature review on the existing MMs and develop one for the sales delivery process of engineeredto-order products. Tiihonen et al. [58] recognize the existence of different stages of maturity of companies regarding product configuration and address the need for an $\mathrm{MM}$ in the software industry, particularly in the configuration of products and processes. Because companies are at different levels of maturity and have various capabilities, the MM must evaluate the company's current state and identify the most effective and efficient way to reach a desirable level of improvement [71]. Furthermore, because the generic maturity assessment frameworks are context dependent [7], there is a need for an assessment method. Based on this idea, we developed and validated a CLM-MM.

\section{Research Method}

The aim of the current article is to develop and validate an MM for CLM. Therefore, the DSR approach is followed because it includes designing and creating IT artifacts (e.g., models, methods, and constructs) and their practical application [72]. In the current research, the DSR approach followed the following two main phases: the development and validation of the CLM-MM. Each phase is divided into two steps $[73,74]$.

Table 1. Research method

\begin{tabular}{|l|l|}
\hline Development phase & Validation phase \\
\hline Step 1: Problem identification & Step 3: Theoretical validation \\
\hline
\end{tabular}


In principle, the DSR approach is structured in a similar way as the one used by Willner et al. [13]. In their research, they use the four-step guideline for $M M$ development based on the procedure developed by Becker et al. [73] and further adapted by Neff et al. [74]. The first two steps are part of the first phase of the DSR approach, and the second phase of DSR consists of steps three and four. The four-step approach provides a deeper level of detail both for the research teams developing the framework and for the research community, allowing for an accurate replication of the study.

The first phase is the development of the IT artifact, where the research method includes the literature review of existing MMs and is based on the outcome of the development of a CLM-MM [12]. The concept of MMs has existed for several decades, and it is considered a well-established practice for evaluating managerial and strategic progress [75]. By gaining a deeper understanding of the development and use of existing MMs, the current research aims at developing a new MM focusing on CLM.

In detail, this first phase is broken down into two steps. The first step is concerned with the identification of the problems. The problems emerging from the industry are described in the introduction (section 1) and then supported by the literature (section 2). The findings indicate that the encapsulation of product knowledge describing all life cycle phases of a configurable product in a universal configuration model is very important in supporting the alignment of IT systems, processes, and resources in an organization. The literature review reveals the need for a systematic approach of handling product models; however, the review points out that frameworks here are lacking. The second step of phase one analyzes the existing MMs to identify if there is a need for developing a new MM. Section 2.2 discusses and evaluates the existing MMs within the field of research.

In the second phase, the CLM-MM is theoretically and empirically validated. The proposed CLM-MM is theoretically evaluated against the existing MMs. Then, the CLM-MM is validated practically during a workshop with a team of experts and in-depth case studies. In detail, this second phase consists of steps three and four. The third step uses the iterative development method. In the current research work, the authors conducted two iterations. The first iteration is the development of the CLM-MM on a conceptual level based on the findings from the literature review and the findings from the initial analysis of the current state in the industry and the problem identification. This step is presented in section 4.1. The second iteration includes an improvement of the theoretically developed MM via validation against existing MMs. This allows the research team to ensure that the developed CLM-MM covers the requirements regarding the configuration process that were not included in the existing models [74].

The fourth step concludes with the empirical validation of the MM. For the validation step, the research team conducted two iterations. The validation process is described and discussed in detail in section 4.2. The first one includes the initial validation, which took place as a focus group workshop with experts in the field of product configuration (described in section 4.2.1). The second iteration uses in-depth case studies, during which three case companies were assessed based on the CLM-MM (described in section 4.2.2). During this evaluation, the research team produced feedback and generated new knowledge about the problem [76]. By following the DSR process, an IT artifact (in this case, a MM) was generated to contribute to practice and theory [77].

\section{Maturity Model for CLM}


According to the literature review, MMs have three to six levels, with each one indicating progress within a specific area [78]. The levels cover the main requirements for an organization to progress from a very initial state to the optimal level. In this research, for designing the CLM-MM, five levels were established primarily because the $\mathrm{MM}$ is based on models for capabilities and capability integration, which generally have five levels. Furthermore, level zero in this case is considered out of the scope of the current research because the MM addresses the integration of CM throughout a product's life cycle. In this case, level zero would be relevant for an organization without an IT system, which is not considered a realistic scenario in the era of Industry 4.0. Therefore, this level was excluded. Figure 3 illustrates a generic MM, including the five levels and five dimensions. In the following section, we discuss the development of the CLM-MM, which is based on a generic MM.

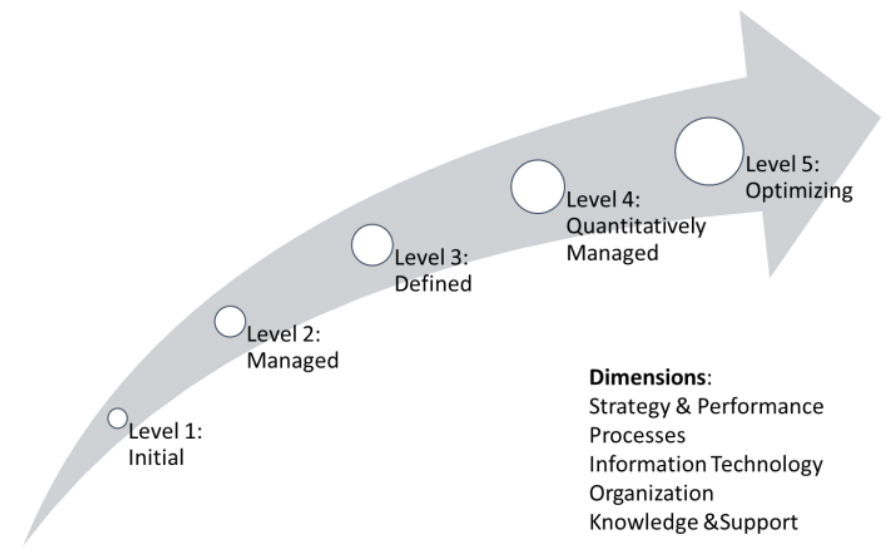

Fig. 3. Generic maturity model (adapted from $[63,70])$.

\subsection{Development of CLM-MM and initial refinement}

This part of the research method focuses on the development and initial refinement of the CLM-MM. Based on the results of the literature review, analytical thinking, and interactions with industry experts, the CLM-MM was developed. To overcome the challenges of the observers' biases while developing the CLM-MM, the research team came from academia and industry to counterbalance possible bias [79], and we ensured that the CLM-MM is based on the literature and has a strong theoretical background, but also a practical application. In addition, although the CLM-MM was developed based on theory, it had to capture the existing needs of the industry in line with the DSR process [76].

The first step in creating the CLM-MM was to define the dimensions of the MM. Based on the literature, the dimensions of the model should cover the relevant discipline of an organization in terms of the product life cycle and CM. The subcategories should follow the same logical structure and describe the specific needs and requirements for the classification of maturity $[7,70]$. For the CLM$\mathrm{MM}$, the primary dimensions were strategy and performance, processes, IT, organization, and knowledge and support. "Strategy and performance" describe the requirements on a strategic level. For instance, the company should have a clear definition of what products it is ready to offer and include in the CLM system [80]. "Processes" include the relevant business processes to support CLM maturity; this is highly relevant for product configuration-related activities because it is through process standardization that the management of the configuration models can be improved [47], especially when this knowledge is used in the different life cycle phases of the product and by different users [51]. "Information technology" describes the tools and level of integration of these tools. For a successful CLM implementation, both the IT systems and business processes should be aligned [11]. 
This means that apart from IT integration on a technical level, the operational level should be taken into account. Therefore, the dimension "organization" addresses the structure of the organization in accordance with the related teams and departments; cross-organizational collaboration and extension to external supply chain stakeholders are considered in this dimension $[43,81]$. "Knowledge and support" define the requirements in terms of knowledge sharing and the accessibility of this knowledge. Improving the $\mathrm{CM}$ policies, along with establishing support and training activities, are factors that influence the success of the implementation of a product configurator [82].

The next step focused on the level-specific requirements. This is the second iteration of the development of the MM. The level-specific requirements for each dimension must be aligned with the scope of the CLM-MM, which is to assess the management of all configuration models throughout a product's life cycle. At the same time, to justify the need for a new MM, these requirements must be aligned with the requirements of product configuration tasks across all life cycle phases of complex configurable products [74]. CLM supports the management of all the configuration models of a product's life cycle processes by using a common approach, not only in the main organization, but also including the external stakeholders. Therefore, the five maturity levels describe the required progress of the organization in the CLM journey; this starts by having a few teams or departments engaged in the CLM vision, which later spreads to all departments and progresses to a cross-organizational engagement, with the final goal of moving beyond the organization by incorporating external stakeholders and aiming for continuous improvement.

The first level (initial capabilities) describes an organization that is starting the CLM journey and is at an initial stage of defining a strategy for full CLM implementation. At this stage, there are no standard methods and processes, and few teams or departments are engaged in the CLM vision. However, establishing a clear CLM strategy is needed, and it should also be aligned with the overall company's strategy [83]. The second level (departmental commitment) describes an organization that is engaged in a silo structure management of configurations. At this level, the scope and strategy of each department for the CLM vision are defined, but few departments have the integration of IT systems and standardized processes. The third level (cross-organizational specialization) describes how the entire organization is engaged in the CLM process with integration and alignment across all departments and processes of the product's life cycle. The fourth level (external-focused expertise) focuses on transferring the CLM vision to external stakeholders and integrating them horizontally into the organization. The fifth level (continuous improvement) describes the optimal stage of CLM in which the organization acts as a benchmark. The processes are fully digitalized and extend beyond the organization, and performance is regularly measured and improved. 


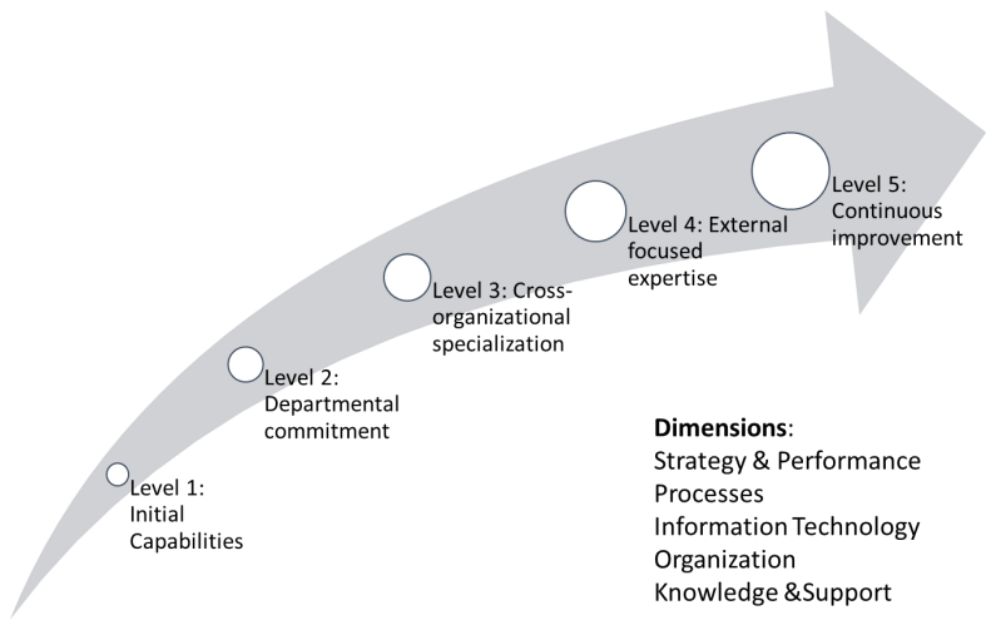

Fig. 4. Configuration life cycle management maturity model.

Based on the above figure, the CLM-MM is presented in Table 2. The model considers the classification of the levels and dimensions of the CLM. The purpose of the MM is to guide an organization to achieve the desired level of CLM maturity because theory indicates that organizations do not evolve much beyond the maturity level of the basic processes of their products in their life cycle phases. If organizations cannot standardize these processes, then the IT system will not make any difference [84]. To do so, the organization must analyze its current state and set goals that describe the desired level [76]. This classification can be performed by conducting an "as-is" and "to-be" analysis of the organization, and based on these results, relevant activities can be defined for the strategic, operational, and tactical levels of the organization.

\subsection{Empirical validation of the CLM-MM}

After the CLM-MM was developed and theoretically validated, the next phase included the empirical validation of the MM by using case research methodology. Here, a case study was selected as the most suitable research method for the current work because the process of validating a CLM-MM is widespread, including when considering its more abstract description, but at the same time, detailed changes are needed at all levels [85]. To do this, the research team conducted two iterations; the first iteration includes a workshop with 50 participants from different companies, and the second iteration includes the validation of the CLM-MM in three case companies that did not participate in the workshop. The main goal of the workshop was to ensure that the MM would cover all configurationrelated aspects of an organization and ensure applicability and external validity. The main goal of the in-depth case studies is to test the robustness of the CLM-MM and further examine the external validity and practical implications of its application.

External validity includes the applicability of the model at different companies in terms of products manufactured, markets, production strategies, size, and country of operation. External validity in terms of the use of the model is addressed by engaging participants with different cultural backgrounds. Multiple respondents ensure less possible biases, and participant subjectivity is overcome [79]. One common characteristic of all the participants-and the respective companies they represented-was that they are experts in the field and have experience in CM in general and in CLM in particular. In addition, all participating companies either manufacture configurable products or work closely with manufacturing companies (e.g., consultants). In addition, the participants in the indepth case studies are all from the manufacturing companies of complex configurable products. 


\subsubsection{First iteration: Workshop}

The duration of the workshop was 70 minutes. The 50 participants were divided into five groups, and each group had to focus on one dimension of the MM while considering all maturity levels. Each group had one facilitator, and there was one overall coordinator among all groups. The facilitator ensured the performance of the sequential activities and time frames and was responsible for guiding the discussion and making sure that one participant did not dominate the discussion. The participants were representatives from 26 different companies. In each group, representatives from different companies were allocated to the workshop to ensure that the input was not subjected to bias and that the discussion would cover a wider range of issues and experiences. Each company was interested in advancing CLM implementation; however, they were at different levels in the CLM journey. The participants were all experts in $\mathrm{CM}$ and held senior positions in their organizations, from engineers to vice presidents.

The research team defined several criteria for selecting the participants to ensure the external validity of the research method $[79,86]$. The variability in the country of occupation, level in the organization/position, and educational background covered a wide range of cultural and educational characteristics. The participants were representatives of large global companies within the industrial machinery and automotive sector, analysts, and consultants within these sectors who all had interest and experience in CLM. The participants were selected to ensure that the model was considered applicable no matter the regional differences, ensuring the generalizability of the research.

A research protocol was used to ensure the reliability and validity of the data [87]. The main question that addressed the validation of the developed MM was as follows: "Which capabilities should an organization demonstrate under each dimension to be placed at the appropriate maturity level?" To ensure the validity and replication of the results [79], the research protocol and list of participants are presented in Appendix A. Each participant wrote down the relevant capabilities for the first 10 minutes. For the next 30 minutes, each participant explained to the rest of the group the capabilities that he or she wrote down, and in the end, the group decided on where to place all the capabilities at the correct level of the MM. In the following 15 minutes, the group gathered the capabilities at each level into common themes. For the last 15 minutes, all groups presented and discussed their results in a plenary session. The comments from the workshop are presented in Appendix B.

The purpose of the research question was to engage the participants in a discussion of the applicability of the model. By analyzing the capabilities of each level and dimension, the participants had to assess whether the model covers all aspects of an organization and whether the levels represent realistic stages. Additionally, the capabilities could be used as more detailed guidelines of assessment when determining the maturity level of an organization. This is another reason why case research was selected; the goal was to determine the sequence of capabilities and activities that lead to CLM maturity within an organization. Therefore, during the workshop, the participants were asked to focus on determining the link between the capabilities and level of maturity (cause-effect relationship) [79]. Focusing on one question during the workshop increased the reliability of the data, making the data more valuable for the research team and leading to more in-depth discussions [79].

\subsubsection{Second iteration: In-depth case studies}

The in-depth case studies include three companies (ALPHA, BETA, GAMMA), all of which are different from the 26 individuals' companies participating in the workshop, hence avoiding possible bias and allowing for a better validation of the outcome $[13,88]$. 
All three companies operate in the industrial equipment and machinery (IE\&M) sector. All three companies are international organizations with more than one billion USD in revenue, operating worldwide and serving business-to-business (B2B) markets globally. Additionally, all three of companies have global distribution networks and production facilities in several locations within Europe, the United States, and Asia. Data collection for the case studies included semi structured interviews with managers and heads of departments, which allowed the research team to gain insights into all the dimensions from the strategic to operational level. Another requirement for selecting the specific case studies is that the case companies must have established product configuration systems that have been utilized for at least three years. The unit of analysis is at the company level to allow for testing for cross-organizational collaboration.

\section{Case company ALPHA:}

ALPHA produces mechanical equipment for the process industry; it provides both individual machinery and total solutions (including several machines), and its customers are in the medical and food industries. ALPHA has been utilizing a product configurator to support the sales processes for the last three years.

Initial state:

Prior to the implementation of the configurator, the sales personnel were using a paper checklist to collect customer requirements. This process was time-consuming and error-prone. After collecting the requirements, the sales person had to insert the parts and products sold into the ERP system. This was also time-consuming, and it always produced several errors. All these errors could happen in the entire process, from collecting the customer requirements until storing them in the database and then forwarding them to the engineering department for the final validation of the feasibility of the product sold.

Current state - Level 1:

In 2014, the company decided to implement a sales configurator. A few months later, the solution was fully integrated into the surrounding IT systems, ERP, and PLM. The entire process of input and output from the sales configurator was designed to be fully automated. The input to the configuration model included the pricing rules, so the generated quotes improved the pricing accuracy of the products sold. The lead time was reduced, and the on-time delivery improved significantly, as reported by the head of the development team. The sales people had a short training and then were able to use the configurator in the sales process. The training and knowledge-sharing activities included the ownership of data and also where the input comes from for each configuration and where the output is being utilized. This eliminated the extra work of maintaining the data in several IT systems and allowed for creating valid and accurate quotes for the customers.

Future state-Level 2:

The company has not defined a desirable future state in terms of CLM improvements. It has been only three years since they started utilizing the sales configurator, and they did not expect such a success regarding the process standardization and elimination of the manual work required. The next step for improvement would be to extend the use of the product configurator across the current silo structure, but there are no concrete plans of how to achieve this goal.

Findings: 
This is an example of a successful implementation of a sales configurator with standardization of both products and processes. The goal was clear from the beginning; the teams involved for developing and setting up the product models were diversified enough to allow for knowledge input from the relevant domains regarding engineering and manufacturing. ALPHA still has a silo solution, but some knowledge and cross-organizational collaboration has been established at the development phase of the sales configurator. The assessment shows that the company's maturity varies across the different dimensions. For instance, the processes around the sales phase are now highly standardized, which is the same for the product portfolio included in the configurator. It can also be argued that IT terms have managed to integrate the configurator with the ERP and PLM system. In terms of organization, the teams included in the configuration project have well-defined roles and responsibilities; however, this is mainly limited to one department within the company, with few individuals being involved from the rest of the company. ALPHA seems to have fulfilled all the requirements to progress its maturity from level 1 to 2; however, it is currently lacking the strategic objectives for how to proceed further.

\section{Case company BETA:}

BETA produces mechanical machinery and equipment for the food industry. It also provides both individual products and full solutions, including a number of machines and individual components. BETA has been utilizing a sales configurator for the last six years.

Initial state:

Before the decision to implement a sales configurator was made, the sales process was based on paper catalogs. The sales personnel had a time-consuming task of collecting the customer requirements and matching them with the product. Several errors were made during this process. Furthermore, the sales people often had to go back to the customer because the solution agreed upon was not feasible or was rejected from the engineering department. BETA reported that there were many errors in this manual process of defining the parts (e.g., numbers) and highlighted that on several occasions, the solution produced ended up not fitting the one actually sold to the customer. Even though the sales people spent a lot of time preparing and validating the quote, mistakes still occurred. They also reported having several iterations between the sales representatives, customer, engineering department, and manufacturing department to avoid having unfit solutions. Additionally, the price estimations were not always accurate.

\section{Current state - Level 1:}

In 2011, BETA decided to implement a product configurator to support its sales phase. In parallel with the development of the configurator, the company conducted a standardization of a part of the product portfolio that was to be included in the configurator. The designs were already standardized, but they improved the overall product model knowledge, for example, identification of the parts and complete products. The requirements the company had set for the implementation of the sales configurator included direct data input from the ERP system. The output required was an automatic quotation generation, which included prices. The company aimed for no manual intervention and a fully automated process to allow for faster and more accurate quote generation. After a product was sold by the sales person, the product data were automatically passed over to the manufacturing department. This has improved the quality of the specifications and reduced the scrap and total lead time. The sales manager mentioned that the sales people have more time to accommodate more customers, which has led to an increase in orders.

Future state - Level 2: 
The next step for the company would be to extend the use of the sales configurator across the entire organization. However, this is a slow process because the company has been in the same situation for the last three years and has seen limited progress. Because the aim is to further improve, the company should benefit from process standardization and be able to include more teams using the configurator, including the development of the product models and the utilizations and maintenance of it. However, the use of the configurator is still limited to a few teams within the sales unit. The main goal should be to include the engineering teams in the configuration project to further improve the standardization of the product designs and provide input to the product models.

Findings:

This is an example of a company that is more mature in the dimensions strategy, performance, and IT but that lacks alignment across the other three dimensions. Even though it has been six years since the utilization of the sales configurator, the company still has not managed to experience the full benefits associated with this change process. The main reason behind this is the limited use of the product configurator to only a part of their product portfolio and one team across the sales people.

\section{Case company GAMMA:}

GAMMA produces electrical equipment for industrial automation and installed base monitoring. Similar to the previous two case companies, GAMMA also provides both individual products and full solutions. GAMMA has been utilizing product configurators to support the engineering and sales phases for the last three years.

Initial state - Level 1:

Prior to and the first year after the implementation of the sales configurator, GAMMA was facing a complex IT landscape. The company developed and utilized several stand-alone product configurators to support the sales phase. GAMMA reported that they started by having more than 50 stand-alone configurators (for different markets or production facilities). In each case, the configurator was integrated into the ERP systems, which were also numerous and location dependent. This situation was the main reason for redundant work when generating a quote, especially when the solution sold to the customer consisted of individual products from different production facilities. Communication across the stakeholders was time-consuming, and the process of collecting the different quotes to generate a complete quote for a full solution was error-prone. The sales personnel reported several errors and inconsistencies among the product configurators and the generated quotes. Furthermore, the cost of maintaining several systems for product data and configuration rules was significant and included a lot of redundant work.

\section{Current state - Level 2:}

To overcome the difficulties and misalignments GAMMA had been experiencing regarding the use of several sales configurators, they started determining in a consistent way the requirements for the sales configurators on a global level. The reason behind this strategic decision was to synchronize and combine the use of the output of the different sales configurators. Another reason for this decision was that the company was aiming to extend the use of product configurators in the engineering and manufacturing phase. Based on this, they developed a product configuration model that included input from experts from sales, engineering, and manufacturing. The first step here was to develop valid and aligned product models for their sales configurators. Then, by using the models and rules developed for the sales phase, they extended their use and knowledge input to these product configuration models to cover the requirements of the engineering and manufacturing phases. 
This task is not completed yet, but they have been experiencing improvements already. This is why the company is described as CLM maturity level 2 but are clearly aiming for level 3. GAMMA already has well-defined roles and responsibilities regarding knowledge sharing across the departments involved in the CLM project. The company also has assigned roles of data ownership across the different departments and clear responsibilities and tasks regarding the maintenance and update of these product data. Finally, GAMMA has also managed to achieve full integration of the IT systems, which leads to more automated processes, discarding the error-prone manual work.

Future state - Level 3:

GAMMA mentions that their goal for the future is to fully integrate engineering, sales, and manufacturing and connect with the PLM and ERP systems. The company is aiming for one global solution. Right now, GAMMA is in the transition from silos to a cross-organizational collaboration across the involved business units (engineering, sales, manufacturing). The company has a welldefined strategy for implementing a full CLM solution that can cover all the life cycle phases of their products; however, for their future state, GAMMA only described the next step in their plan, not the overall end goal.

Findings:

This is an example of a company with aligned maturity across all five dimensions. GAMMA achieved the same maturity level across all dimensions and then moved to the next maturity level, including process standardization, well-defined deployment strategy, cross-organization engagement, welldefined roles and responsibilities across the different teams, and knowledge transfer, including lesson learned across the different departments involved. GAMMA has a very clear strategy on how to improve their CLM maturity; therefore, GAMMA has achieved these results within three years and is aiming for a full CLM implementation within the coming years.

Based on the findings of the three case companies, the research team mapped them on the CLM-MM. Table 3 illustrates how each case study experiences each dimension of its maturity level.

Table 2. Case studies mapping on CLM-MM.

\begin{tabular}{|c|c|c|c|c|c|c|}
\hline Case & $\begin{array}{l}\text { Maturity } \\
\text { Level }\end{array}$ & $\begin{array}{l}\text { Strategy and } \\
\text { Performance }\end{array}$ & Processes & $\begin{array}{l}\text { Information } \\
\text { Technology }\end{array}$ & Organization & $\begin{array}{l}\text { Knowledge and } \\
\text { Support }\end{array}$ \\
\hline & 1 & $\begin{array}{l}\text { Sales } \\
\text { configurators, } \\
\text { pricing and } \\
\text { quotation, } \\
\text { product } \\
\text { standardization }\end{array}$ & $\begin{array}{l}\text { Automated } \\
\text { process of input } \\
\text { and output of } \\
\text { sales } \\
\text { configurator, } \\
\text { elimination of } \\
\text { manual work }\end{array}$ & $\begin{array}{l}\text { Integration to } \\
\text { ERP and PLM }\end{array}$ & $\begin{array}{l}\text { Sales people, } \\
\text { one department } \\
\text { involved with } \\
\text { clear roles }\end{array}$ & $\begin{array}{l}\text { Training for new } \\
\text { hires }\end{array}$ \\
\hline$\frac{\nwarrow}{\frac{\pi}{2}}$ & 2 & $\begin{array}{l}\text { Extend the use } \\
\text { of the sales } \\
\text { configurator } \\
\text { across the } \\
\text { organization }\end{array}$ & Not defined & Not defined & $\begin{array}{l}\text { Include more } \\
\text { cross- } \\
\text { departmental } \\
\text { teams and move } \\
\text { from the silo } \\
\text { structure }\end{array}$ & Not defined \\
\hline$\underset{\infty}{\mathbb{\infty}}$ & 1 & $\begin{array}{l}\text { Sales } \\
\text { configurator, } \\
\text { generating } \\
\text { quotations, } \\
\text { including pricing }\end{array}$ & $\begin{array}{l}\text { Standardization } \\
\text { and automation } \\
\text { of sales process }\end{array}$ & $\begin{array}{l}\text { Input from ERP, } \\
\text { output to } \\
\text { manufacturing } \\
\text { IT system (ERP) }\end{array}$ & $\begin{array}{l}\text { Involved } \\
\text { members mainly } \\
\text { from the sales } \\
\text { team, and a few } \\
\text { from the } \\
\text { engineering } \\
\text { department for } \\
\text { standardization }\end{array}$ & $\begin{array}{l}\text { Improvements } \\
\text { in product } \\
\text { modeling } \\
\text { knowledge } \\
\text { through } \\
\text { portfolio } \\
\text { standardization }\end{array}$ \\
\hline
\end{tabular}




\begin{tabular}{|c|c|c|c|c|c|c|}
\hline & & & & & $\begin{array}{l}\text { of product } \\
\text { models }\end{array}$ & \\
\hline & 2 & $\begin{array}{l}\text { Implementation } \\
\text { and utilization of } \\
\text { a sales } \\
\text { configurator } \\
\text { across the entire } \\
\text { organization }\end{array}$ & $\begin{array}{l}\text { Further improve } \\
\text { process } \\
\text { standardization } \\
\text { mainly on sales } \\
\text { and some parts } \\
\text { of engineering }\end{array}$ & Not defined & $\begin{array}{l}\text { Extend to the } \\
\text { entire sales } \\
\text { organization and } \\
\text { include } \\
\text { engineering } \\
\text { teams for input } \\
\text { to product } \\
\text { models }\end{array}$ & $\begin{array}{l}\text { Improve } \\
\text { product design } \\
\text { standardization }\end{array}$ \\
\hline \multirow[b]{3}{*}{ 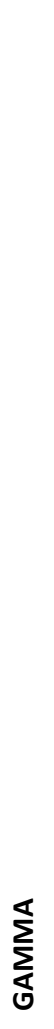 } & 1 & $\begin{array}{l}\text { Improve sales } \\
\text { processes }\end{array}$ & $\begin{array}{l}\text { Quote } \\
\text { generation } \\
\text { automated, but } \\
\text { for complex } \\
\text { quotes manual } \\
\text { work required }\end{array}$ & $\begin{array}{l}\text { Numerous } \\
\text { stand-alone } \\
\text { sales } \\
\text { configurators } \\
\text { (more than 50), } \\
\text { numerous ERP } \\
\text { systems }\end{array}$ & $\begin{array}{l}\text { Location } \\
\text { dependent } \\
\text { (geographically) }\end{array}$ & $\begin{array}{l}\text { Silo-structured } \\
\text { knowledge } \\
\text { sharing and } \\
\text { accessibility }\end{array}$ \\
\hline & 2 & $\begin{array}{l}\text { Connect and } \\
\text { align sales } \\
\text { configurators, } \\
\text { introduce } \\
\text { engineering } \\
\text { configurators }\end{array}$ & $\begin{array}{l}\text { Establish } \\
\text { requirements } \\
\text { for sales } \\
\text { configurators on } \\
\text { a global level for } \\
\text { automated } \\
\text { processes }\end{array}$ & $\begin{array}{l}\text { Synchronization } \\
\text { and alignment } \\
\text { of sales and } \\
\text { engineering } \\
\text { configurators } \\
\text { along with the } \\
\text { rest of IT } \\
\text { systems }\end{array}$ & $\begin{array}{l}\text { Well-defined } \\
\text { roles and } \\
\text { responsibilities, } \\
\text { data ownership } \\
\text { and } \\
\text { maintenance } \\
\text { across involved } \\
\text { departments }\end{array}$ & $\begin{array}{l}\text { Experts from } \\
\text { engineering, } \\
\text { sales and } \\
\text { manufacturing } \\
\text { departments }\end{array}$ \\
\hline & 3 & $\begin{array}{l}\text { Connect and } \\
\text { align } \\
\text { engineering, } \\
\text { sales, and } \\
\text { manufacturing } \\
\text { product } \\
\text { configurators }\end{array}$ & $\begin{array}{l}\text { Fully automated } \\
\text { configuration } \\
\text { processes } \\
\text { across } \\
\text { engineering, } \\
\text { sales and } \\
\text { manufacturing } \\
\text { on a global level }\end{array}$ & $\begin{array}{l}\text { Full integrations } \\
\text { and alignment } \\
\text { across the } \\
\text { product } \\
\text { configurators, } \\
\text { ERP and PLM } \\
\text { systems }\end{array}$ & $\begin{array}{l}\text { Cross- } \\
\text { organizational } \\
\text { collaboration of } \\
\text { involved teams } \\
\text { on a global level } \\
\text { across } \\
\text { departments } \\
\text { (engineering, } \\
\text { sales, } \\
\text { manufacturing) }\end{array}$ & $\begin{array}{l}\text { Product model } \\
\text { including rules } \\
\text { from } \\
\text { engineering, } \\
\text { sales and } \\
\text { manufacturing, } \\
\text { generated } \\
\text { specifications } \\
\text { for sales, } \\
\text { engineering, } \\
\text { and } \\
\text { manufacturing }\end{array}$ \\
\hline
\end{tabular}

\section{Results and Discussion}

In this section, the results of the research are discussed. The DSR process is followed because it focuses on the theoretical and practical application of IT artifacts [72]. The process is described at a more detailed level using four steps [13] to provide a deeper understanding regarding the development and the validation of the CLM-MM. Because the CLM-MM was developed by the research group and validated against literature, its practical aspect had to be validated too. In this case, an iterative validation process was followed. During the first iteration, the workshop was conducted to provide empirical validation of the proposed CLM-MM by experts in terms of its relevance and applicability in the industry following the DSR process [76]. Based on the discussions among the groups during the workshop, the model seemed to cover the most important issues that companies face when integrating product configurators. None of the groups or participants mentioned anything was missing or that an area had been overlooked by the CLM-MM. Therefore, the comments and discussions added details to each dimension and the levels of the MM for the required capabilities. The second iteration included in-depth case studies. The three case companies were evaluated in terms of their CLM maturity using the developed MM. The case companies vary in terms of their current maturity level and in the way they have reached this level. There is also variation among the desirable maturity level that each case company aims for and how each one is planning to achieve it. 
In terms of vertical categorization, the maturity model describes the transition from a type of silo organizational engagement to a cross-functional organization that extends to external stakeholders. The workshop groups agreed on this distinction because it represented a realistic picture of the current and targeted CLM maturity in their organizations. Based on the current need to expand integration [19], first, the organization has to engage and align all of their internal resources, such as teams, departments, and business units. The first three levels of the MM describe this transition, from a silo organization to a cross-functional organization regarding configuration knowledge. Then, level 4 is where the organization is considered mature enough and has all the internal processes and product models aligned; thus, the organization can start including external stakeholders in standard processes and data exchanges of configuration definitions and configurations. This aligns with the literature that indicates that value is created for customers when the business processes are integrated, including suppliers and customers, beyond the boundaries of the organization $[89,90]$.

The purpose of the CLM-MM is to guide manufacturing companies to improve the management of their complex configurable products across the life cycle. Hence, the suggested CLM-MM follows the potential performance perspective [75], meaning that the MM shows a way to develop regarding CLM while at the same time allowing the user to decide on the optimum level of maturity in each case.

In terms of horizontal categorization, one issue that is common within all dimensions was the impact of complexity at the different levels: not only the complexity of the configuration models, but also the complexity of the processes and organization. The CLM-MM can facilitate this complexity by guiding an organization toward a structured approach to share configuration knowledge and data across and beyond an organization. These findings are also in line with the literature because the increasing complexity of products, processes, and amount of data are concerns addressed in the application of configuration and PLM systems [34].

The workshop participants discussed how their organizations would be rated based on the CLM-MM. Most identified themselves among levels one and two. Only two out of the 50 participants could argue for being classified at level 3 because of collaboration across different departments and/or locations of their organizations. Another participant mentioned that his company is more mature in one dimension (IT) compared with the other dimensions of the CLM-MM.

Regarding the findings from the in-depth case studies, ALPHA and BETA are assigned to CLM maturity level 1. Both have been using product configurators to support their sales processes. The involvement of different teams in the development, maintenance, and use of the product configurator is different for both cases, and this is apparent both in the number years each company has spent to reach maturity level 1 and their plans to further their maturity regarding CLM. On the other hand, GAMMA is the best-performing example regarding CLM maturity. Based on the findings of the maturity evaluation, GAMMA seems to be moving first horizontally on the CLM-MM, achieving a certain maturity level across all five dimensions and then moving vertically to the next maturity level. Another result from the evaluation of the case studies is that not every case addresses aspects that are relevant to each and every dimension. This could be explained by the difference in the maturity level; ALPHA and BETA are less mature compared with GAMMA, and they do not address all dimensions in their future maturity states. Even though these two companies have plans for further progressing and expanding the use of product configurations, they are lacking a structured approach to develop a holistic plan. On the contrary, GAMMA, which is more mature even regarding future steps, addresses all the dimensions.

The case studies provide empirical validation to the first three maturity levels. CLM maturity levels 4 and 5 have not been achieved by either the three in-depth case studies or the 26 case companies 
participating in the workshop. These maturity levels have been validated against the literature. However, the fact that none of the companies have a higher maturity level than level 3 can be explained by the lack of a systematic approach to guide the organization through the transition [7]. Another possible explanation is that CLM is a new concept that is generated from the needs of the industry and supported by the literature; hence, companies are currently going through this transition and have not reached the final maturity level in CLM [1].

The findings from both the workshop and in-depth case studies demonstrate the need for more concrete tools and material to ensure that each organization fulfills the specific criteria to be ranked at the different levels. The CLM-MM needs to be more operationalized by, for example, a structured questionnaire to allow for assessing the CLM maturity of individual organizations [11]. Supplementing the generic CLM-MM with questionnaires and methods for measuring configuration-related performance indicators would also lead to developing more industry-specific applications of the CLMMM [7].

Based on this, we could argue that the main limitation of the current research in terms of the generalizability of the results is that the model was tested in case companies from the IE\&M sector. The validation of the CLM-MM during the workshop by industry experts, the in-depth case studies, and the validation against the literature is a first step. The findings of the research match with the literature and contribute to the discussion regarding the need for an extension of the product configuration ontology in terms of life cycle phases and across organizations [4]. However, the CLMMM must be further tested in depth in a wider industrial range of manufacturing companies that have complex configurable products, helping to verify the specific assessment criteria for moving from one level to the next. To do so, additional assessment tools are required to allow this general CLM-MM to be adopted for application in specific companies across different industries. These supplementary tools should include questionnaires for data collection to assess the maturity level per dimension in each case study [13]. As an overall impression from the workshop, the participants were engaged in the discussion and showed interest in the group presentations. Regarding the case studies, the companies' assessments, apart from the identification of maturity levels, also provide insight into how companies are experiencing the transition from one level maturity to the next. Therefore, the present version of the CLM-MM seems to have some direct practical application, even without having any assessment tools yet.

\section{Conclusions and Future Research}

The current paper presents the development and validation of a CLM-MM. The purpose of this model is to assess the CLM maturity level of an organization. CLM addresses the management of configuration models and configured products (e.g., specifications, product variants, knowledge models, and IT systems) across all business processes that are applied throughout the life cycle of a product. CLM emerges from the needs of the industry; manufacturers anticipate having a coherent method for handling configuration knowledge and data across all the life cycle phases of a product. However, a systematic approach toward handling this challenge is lacking in the literature.

To answer the research question, the research team developed the CLM-MM based on existing models in operations management theory by following the DSR process. The model captures all dimensions related to CLM within an organization: strategy and performance, processes, IT, organization, and knowledge and support. The model also represents and guides the transition from a silo to a crossorganizational integration of CLM, starting from small teams in some departments of the organization that can be extended to horizontal integration of external stakeholders. The CLM-MM was validated against theory and in practice; first, via a workshop, industry representatives were asked to assess the 
applicability of the model and discuss the capabilities an organization needs to qualify for each level; next in-depth case studies were carried out, where three case companies were evaluated using the CLM-MM.

The present paper contributes to the theory of $\mathrm{CM}$, in particular $\mathrm{CLM}$, by developing a structured method for describing and evaluating CLM within an organization and extending the model to include suppliers, vendors, and so forth. Furthermore, the model contributes to practice by providing practitioners with a tool for systematically guiding users to assess the current state of an organization and how to advance in implementing CLM.

Future research should include testing the model with several case studies from a broader range of industries to gain a better in-depth understanding of the model's capabilities and to develop more concrete assessment criteria. Case companies manufacturing complex configurable products should be included in future research to further test the CLM-MM, validate the supplementary tools, and measure the impact and benefits at each maturity level. 
Table 2. Configuration life cycle management maturity model (CLM-MM).

\begin{tabular}{|c|c|c|c|c|c|}
\hline Maturity Level & Strategy and Performance & Processes & Information Technology & Organization & Knowledge and Support \\
\hline 1 Initial capabilities & $\begin{array}{l}\text { CLM strategic objective and } \\
\text { policy: Define the mission, } \\
\text { vision, and goals for the CLM } \\
\text { journey }\end{array}$ & $\begin{array}{l}\text { Standard processes in one } \\
\text { or more configuration life } \\
\text { cycle phases for the } \\
\text { relevant organizational } \\
\text { departments }\end{array}$ & $\begin{array}{l}\text { Identification of the IT systems used } \\
\text { until now, an evaluation based on } \\
\text { knowledge and data sharing, and } \\
\text { implementation of stand-alone IT } \\
\text { system(s) to support selected } \\
\text { configuration life cycle phases }\end{array}$ & $\begin{array}{l}\text { Dedicated teams or } \\
\text { departments as part of } \\
\text { the organization to } \\
\text { support the CLM journey }\end{array}$ & $\begin{array}{l}\text { Common CLM terminology and } \\
\text { knowledge support accessible to relevant } \\
\text { organizational departments. Data } \\
\text { availability is limited and not shared } \\
\text { cross-organizationally }\end{array}$ \\
\hline $\begin{array}{l}2 \text { Departmental } \\
\text { commitment }\end{array}$ & $\begin{array}{l}\text { Deployment of CLM strategy } \\
\text { at different levels of the } \\
\text { organization: define the } \\
\text { scope of deployment for each } \\
\text { department and the roadmap } \\
\text { to achieve the goals }\end{array}$ & $\begin{array}{l}\text { Standard processes for all } \\
\text { the configuration life cycle } \\
\text { phases of the products and } \\
\text { services }\end{array}$ & $\begin{array}{l}\text { Selected cross-organization } \\
\text { integration of each stand-alone IT } \\
\text { system with relevant configuration } \\
\text { life cycle phases }\end{array}$ & $\begin{array}{l}\text { Well-defined roles, } \\
\text { responsibilities, and tasks } \\
\text { for the teams and } \\
\text { departments involved in } \\
\text { CLM }\end{array}$ & $\begin{array}{l}\text { CLM-related training activities } \\
\text { (processes, IT, etc.) to support and } \\
\text { transfer knowledge to all levels of the } \\
\text { relevant organizational departments }\end{array}$ \\
\hline $\begin{array}{c}3 \text { Cross-organizational } \\
\text { specialization }\end{array}$ & $\begin{array}{l}\text { Communication of deployed } \\
\text { CLM strategy to stakeholders, } \\
\text { distribute activities, and } \\
\text { responsibilities for each } \\
\text { stakeholder }\end{array}$ & $\begin{array}{l}\text { Well-defined ownership, } \\
\text { maintenance, and updates } \\
\text { based on feedback from } \\
\text { each process supporting } \\
\text { the CLM goals }\end{array}$ & $\begin{array}{l}\text { Cross-organizational integration and } \\
\text { alignment of IT systems with the } \\
\text { CLM system for all configuration life } \\
\text { cycle phases }\end{array}$ & $\begin{array}{l}\text { Cross-organizational } \\
\text { collaboration on CLM } \\
\text { tasks among internal } \\
\text { stakeholders }\end{array}$ & $\begin{array}{l}\text { Engage cross-organizational teams in } \\
\text { knowledge sharing and training: } \\
\text { accessibility and promotion of latest } \\
\text { standards, best practices, lessons } \\
\text { learned, and data foundation for CLM }\end{array}$ \\
\hline 4 External-focused expertise & $\begin{array}{l}\text { Clear definition of CLM- } \\
\text { related key performance } \\
\text { indicators for performance } \\
\text { measurements }\end{array}$ & $\begin{array}{l}\text { External stakeholders are } \\
\text { included in the CLM } \\
\text { processes and integrated } \\
\text { horizontally in the } \\
\text { organization }\end{array}$ & $\begin{array}{l}\text { Integrations of external } \\
\text { stakeholders' systems to the CLM } \\
\text { system }\end{array}$ & $\begin{array}{l}\text { The organization has a } \\
\text { dedicated team or } \\
\text { department to engage } \\
\text { external stakeholders in } \\
\text { CLM }\end{array}$ & $\begin{array}{l}\text { Universal data foundation to support } \\
\text { shared CLM knowledge base and training } \\
\text { between the organization and engaged } \\
\text { external parties }\end{array}$ \\
\hline 5 Continuous improvement & $\begin{array}{l}\text { Regular measurement and } \\
\text { update of KPIs, benchmarking } \\
\text { with other CLM organizations, } \\
\text { continuous cross-organization } \\
\text { integration, and improvement }\end{array}$ & $\begin{array}{l}\text { Customized processes to } \\
\text { cover different products } \\
\text { and services, configuration } \\
\text { life cycle processes fully } \\
\text { digitalized and used by } \\
\text { internal and external } \\
\text { stakeholders }\end{array}$ & $\begin{array}{l}\text { Unified IT architecture to support all } \\
\text { CLM processes and activities; } \\
\text { responsibility for the CLM system } \\
\text { clearly defined by the stakeholders }\end{array}$ & $\begin{array}{l}\text { Any change in CLM } \\
\text { communicated to the } \\
\text { stakeholders and } \\
\text { immediately adopted by } \\
\text { the whole organization } \\
\text { and its external parties }\end{array}$ & $\begin{array}{l}\text { Share knowledge with other CLM } \\
\text { organizations to continuously improve } \\
\text { the CLM knowledge base }\end{array}$ \\
\hline
\end{tabular}




\section{References}

[1] M. Colledani, W. Terkaj, T. Tolio, M. Tomasella, Development of a Conceptual Reference Framework to Manage Manufacturing Knowledge Related to Products, Processes and Production Systems, in: A. Bernard, S. Tichkiewitch (Eds.), Methods Tools Eff. Knowl. LifeCycle-Management, Springer, Berlin, Heidelberg, 2008. doi:10.1007/978-3-540-78431-9_15.

[2] L. Hvam, J. Riis, N.H. Mortensen, Product customization, Springer, Berlin Heidelberg, 2008.

[3] M. Borsato, Bridging the gap between product lifecycle management and sustainability in manufacturing through ontology building, Comput. Ind. 65 (2014) 258-269. doi:10.1016/j.compind.2013.11.003.

[4] L.L. Zhang, Product configuration: a review of the state-of-the-art and future research, Int. J. Prod. Res. 52 (2014) 6381-6398. doi:10.1080/00207543.2014.942012.

[5] J. Batchelor, H.R. Andersen, Bridging the Product Configuration Gap Between PLM and ERP An Automotive Case Study, in: Proc. 19th Int. Prod. Dev. Manag. Conf., University of Manchester, U.K., 2012: pp. 17-19.

[6] A. Sääksvuori, A. Immonen, Product lifecycle management, Springer, 2008.

[7] H. Kärkkäinen, J. Myllärniem, Maturity assessment for implementing and using product lifecycle management in project-oriented engineering companies, Int. J. Electron. Bus. 11 (2014) 176-198. doi:10.1504/IJEB.2014.060218.

[8] T. De Bruin, R. Freeze, U. Kaulkarni, M. Rosemann, Understanding the Main Phases of Developing a Maturity Assessment Model, in: Australas. Conf. Inf. Syst., New SouthWales, Sydney, 2005: pp. 8-19. doi:10.1108/14637151211225225.

[9] A. Myrodia, T. Randrup, L. Hvam, Configuration Lifecycle Management - An assessment of the benefits based on maturity, in: A. Felfernig, J. Tiihonen, L. Hotz, M. Stettinger (Eds.), Proc. 20th Int. Config. Work., University of Hamburg, Graz, Austria, 2018: pp. 119-124. https://www.eventhelpr.com/files/events/h7K8dUz3vdCH87URzYD4rgxa/attachments/proce edings-configuration-workshop-2018_YsITwntH.pdf.

[10] A. Bernard, L. Rivest, D. Dutta, M. Niknam, J. Ovtcharova, Towards Higher Configuration Management Maturity, in: A. Bernard, L. Rivest, D. Dutta (Eds.), Prod. Lifecycle Manag. Soc. PLM 2013. IFIP Adv. Inf. Commun. Technol., Springer, Berlin, Heidelberg, 2013: pp. 396-405. doi:10.1007/978-3-642-41501-2_40.

[11] R. Batenburg, R.W. Helms, J. Versendaal, PLM roadmap: stepwise PLM implementation based on the concepts of maturity and alignment, Int. J. Prod. Lifecycle Manag. 1 (2006) 333. doi:10.1504/IJPLM.2006.011053.

[12] R. Beck, S. Weber, R.W. Gregory, Theory-generating design science research, Inf. Syst. Front. 15 (2013) 637-651. doi:10.1007/s10796-012-9342-4.

[13] O. Willner, J. Gosling, P. Schönsleben, Establishing a maturity model for design automation in sales-delivery processes of ETO products, Comput. Ind. 82 (2016) 57-68. doi:10.1016/j.compind.2016.05.003.

[14] T. Soininen, J. Tiihonen, T. Männistö, R. Sulonen, Towards a general ontology of configuration, Artif. Intell. Eng. Des. Anal. Manuf. 12 (1998) 357-372. https://wwwcambridge-org.proxy.findit.dtu.dk/core/services/aop-cambridge- 
core/content/view/00DC46E000815FDB7A68EF19661AC11E/S089006049812408Xa.pdf/towa rds_a_general_ontology_of_configuration.pdf (accessed November 6, 2017).

[15] A. Haug, L. Hvam, N.H. Mortensen, Definition and evaluation of product configurator development strategies, Comput. Ind. 63 (2012) 471-481.

doi:10.1016/j.compind.2012.02.001.

[16] H.-E. Tseng, C.-C. Chang, S.-H. Chang, Applying case-based reasoning for product configuration in mass customization environments, Expert Syst. Appl. 29 (2005) 913-925. doi:10.1016/j.eswa.2005.06.026.

[17] M. Aldanondo, S. Rougé, M. Véron, Expert configurator for concurrent engineering : Caméléon on software and model, J. Intell. Manuf. 11 (2000) 127-134.

[18] C. Forza, F. Salvador, Product con guration and inter-firm coordination: an innovative solution from a small manufacturing enterprise, Comput. Ind. (2002).

[19] M. Heiskala, J. Tiihonen, K.-S. Paloheimo, T. Soininen, Mass Customization with Configurable Products and Configurators: A review of benefits and challenges, in: Mass Cust. Pers. Commun. Environ. Integr. Hum. Factors, IGI Global, 2009: pp. 75-106. doi:10.4018/978-160566-260-2.ch006.

[20] L. Hvam, S. Pape, M.K. Nielsen, Improving the quotation process with product configuration, Comput. Ind. 57 (2006) 607-621. doi:10.1016/j.compind.2005.10.001.

[21] Z. Hua, F. Huang, B. Zhang, Process flexibility with bill of material constraints, Int. J. Prod. Res. 46 (2008) 1567-1586. doi:10.1080/00207540600969766.

[22] R. Studer, R. Benjaminsc, D. Fensela, Knowledge engineering: Principles and methods, Data Knowl. Eng. 25 (1998) 161-197. doi:10.1016/S0169-023X(97)00056-6.

[23] C. Forza, F. Salvador, Product Information Management for Mass Customization, Palgrave Macmillan, Basingstoke, United Kingdom, 2006.

[24] J. Stark, Product Lifecycle Management, in: Prod. Lifecycle Manag. (Volume 2), Springer, Cham, 2016: pp. 1-35. doi:10.1007/978-3-319-24436-5_1.

[25] H.L. Lee, V. Padmanabhan, S. Whang, Information Distortion in a Supply Chain: The Bullwhip Effect, Manage. Sci. 50 (2004) 1875-1886. doi:10.1287/mnsc.1040.0266.

[26] L.L. Zhang, Product configuration: a review of the state-of-the-art and future research, Int. J. Prod. Res. 52 (2014) 6381-6398. doi:10.1080/00207543.2014.942012.

[27] S.Y. Nof, G. Morel, L. Monostori, A. Molina, F. Filip, From plant and logistics control to multienterprise collaboration: Milestone report of the Manufacturing and Logistics Systems Coordinating Committee, Annu. Rev. Control. 30 (2015) 55-68. doi:10.1.1.556.1803.

[28] J. Hojlo, IDC MaturityScape: Product Innovation Platform 1.0, 2016. https://www.idc.com/getdoc.jsp?containerld=US40541016 (accessed November 1, 2017).

[29] W. ElMaraghy, H. ElMaraghy, T. Tomiyama, L. Monostori, Complexity in engineering design and manufacturing, CIRP Ann. - Manuf. Technol. 61 (2012) 793-814. doi:10.1016/j.cirp.2012.05.001.

[30] S. Wiesner, M. Freitag, I. Westphal, K.-D. Thoben, Interactions between Service and Product Lifecycle Management, Procedia CIRP. 30 (2015) 36-41. https://ac-els-cdncom.proxy.findit.dtu.dk/S2212827115000578/1-s2.0-S2212827115000578main.pdf?_tid=bb95f4f8-c2f1-11e7-ad8f- 
00000aab0f6c\&acdnat=1509973095_59bebbfa23d5600a14c69d8632ea94c0 (accessed November 6, 2017).

[31] N. Penaranda, R. Mejia, D. Romero, A. Molina, Implementation of product lifecycle management tools using enterprise integration engineering and action-research, Int. J. Comput. Integr. Manuf. 23 (2010) 853-875. doi:10.1080/0951192X.2010.495136.

[32] L.L. Zhang, E. Vareilles, M. Aldanondo, Generic bill of functions, materials, and operations for SAP2 configuration, Int. J. Prod. Res. 51 (2013) 465-478. doi:10.1080/00207543.2011.652745.

[33] Z. Chen, L. Wang, Adaptable product configuration system based on neural network, Int. J. Prod. Res. 47 (2009) 5037-5066. doi:10.1080/00207540802007571.

[34] S. Zina, M. Lombard, L. Lossent, Integration of contextual views in configuration management for PLM applications, IFAC Proc. Vol. 39 (2006) 225-231. doi:10.3182/20060522-3-FR2904.00036.

[35] E. Zancul, PLM Reference Model: A Preliminary Proposal for Reference Model Evolution, in: L. Rivest, A. Bouras, B. Louhichi (Eds.), Adv. Inf. Commun. Technol., Springer, Berlin, Heidelberg, 2012: pp. 525-534. doi:10.1007/978-3-642-35758-9_47.

[36] A. Corallo, M.E. Latino, M. Lazoi, S. Lettera, M. Marra, S. Verardi, Defining Product Lifecycle Management: A Journey across Features, Definitions, and Concepts, ISRN Ind. Eng. (2013) 110. doi:https://doi.org/10.1155/2013/170812.

[37] Z. Souheïl, M. Lombard, L. Lossent, C. Henriot, Generic Modeling and Configuration Management in Product Lifecycle Management, Int. J. Comput. Commun. Control. 1 (2006) 126-138. http://univagora.ro/jour/index.php/ijccc/article/view/2314/786 (accessed January 30, 2018).

[38] S.G. Lee, Y.-S. Ma, G.L. Thimm, J. Verstraeten, Product lifecycle management in aviation maintenance, repair and overhaul, (2007). doi:10.1016/j.compind.2007.06.022.

[39] International Organization for Standardization, Quality management systems : Guidelines for configuration management, (2003) 18. http://cds.cern.ch/record/1208404 (accessed October 24, 2017).

[40] T.F. Burgess, D. McKee, C. Kidd, Configuration management in the aerospace industry: a review of industry practice, Int. J. Oper. Prod. Manag. 25 (2005) 290-301. doi:10.1108/01443570510581880.

[41] Institute of Process Excellence (IpX), Institute of Process Excellence (IpX), What Is Config. Manag. (2017). https://icmhq.com/insight/what-is-configuration-management/ (accessed October 23, 2017).

[42] R. Jardim-Goncalves, A. Grilo, A. Steiger-Garcao, Developing Interoperability in Mass Customization Information Systems, in: T. Blecker, G. Friedrich (Eds.), Mass Cust. Inf. Syst. Bus., Information Science Reference, 2007: pp. 136-161.

[43] T. Blecker, N. Abdelkafi, G. Kreutler, G. Friedrich, Product configuration systems: state of the art, conceptualization and extensions, in: Proc. Eight Maghrebian Conf. Softw. Eng. (MCSEAI 2004), 2004: pp. 25-36.

[44] J. Stark, Product Lifecycle Management: Paradigm for 21st Century Product Realisation, Publication of Landmark PLM Book, 2004..

[45] E. Subrahmanian, S. Rachuri, S.J. Fenves, S. Foufou, R.D. Sriram, Product lifecycle 
management support: a challenge in supporting product design and manufacturing in a networked economy, Int. J. Prod. Lifecycle Manag. 1 (2005) 4-25.

doi:10.1504/IJPLM.2005.007342.

[46] M. Rüßmann, M. Lorenz, P. Gerbert, M. Waldner, J. Justus, P. Engel, M. Harnisch, Industry 4.0. The Future of Productivity and Growth in Manufacturing, Bost. Consult. (2015) 1-5.

[47] Aberdeen Group, The Configuration Management Benchmark Report, (2007) 27.

[48] A. Myrodia, K. Kristjansdottir, L. Hvam, Impact of product configuration systems on product profitability and costing accuracy, Comput. Ind. Ind. 88 (2017) 12-18. doi:10.1016/j.compind.2017.03.001.

[49] A. Myrodia, K. Kristjansdottir, S. Shafiee, L. Hvam, Product configuration system and its impact on product's life cycle complexity, in: 2016 IEEE Int. Conf. Ind. Eng. Eng. Manag., IEEE, Bali, Indonesia, 2016: pp. 670-674. doi:10.1109/IEEM.2016.7797960.

[50] P. Goldsack, J. Guijarro, S. Loughran, A. Coles, A. Farrell, A. Lain, P. Murray, P. Toft, The SmartFrog Configuration Management Framework, Oper. Syst. Rev. - Assoc. Comput. Mach. 43 (2009) 16-25. doi:10.1145/1496909.1496915.

[51] D. Monticolo, J. Badin, S. Gomes, E. Bonjour, D. Chamoret, A meta-model for knowledge configuration management to support collaborative engineering, Comput. Ind. 66 (2015) 1120. doi:10.1016/j.compind.2014.08.001.

[52] M. Aldanondo, E. Vareilles, M. Djefel, Towards an association of product configuration with production planning, Int. J. Mass Cust. 3 (2010) 316-332.

http://www.inderscienceonline.com.proxy.findit.dtu.dk/doi/pdf/10.1504/IJMASSC.2010.0376 48 (accessed October 30, 2017).

[53] K. Schierholt, Process configuration: Combining the principles of product configuration and process planning, Artif. Intell. Eng. Des. Anal. Manuf. 15 (2001) 411-424. https://wwwcambridge-org.proxy.findit.dtu.dk/core/services/aop-cambridgecore/content/view/6CF46552531A24F4C97482EEFBA4528D/S0890060401155046a.pdf/proc ess_configuration_combining_the_principles_of_product_configuration_and_process_planni ng.pdf (accessed October 30, 2017).

[54] D. Campagna, A. Formisano, Product and Production Process Modeling and Configuration, Fundam. Informaticae. 124 (2013) 403-425. doi:10.3233/FI-2013-841.

[55] P. Pitiot, M. Aldanondo, E. Vareilles, P. Gaborit, M. Djefel, S. Carbonnel, Concurrent product configuration and process planning, towards an approach combining interactivity and optimality, Int. J. Prod. Res. 51 (2013) 524-541. doi:10.1080/00207543.2011.653449.

[56] P. Pitiot, M. Aldanondo, E. Vareilles, Concurrent product configuration and process planning: Some optimization experimental results, Comput. Ind. 65 (2014) 610-621. doi:10.1016/j.compind.2014.01.012.

[57] L.L. Zhang, P.T. Helo, An empirical study on product configurators' application: Implications, challenges and opportunities, in: CEUR Workshop Proc., 2015: pp. 5-10.

[58] J. Oh, S. Lee, J. Yang, A collaboration model for new product development through the integration of PLM and SCM in the electronics industry, Comput. Ind. 73 (2015) 82-92. doi:10.1016/j.compind.2015.08.003.

[59] O. González-Rojas, L. Ochoa-Venegas, A decision model and system for planning and adapting the configuration of enterprise information systems, Comput. Ind. 92-93 (2017) 161-177. 
doi:10.1016/j.compind.2017.08.004.

[60] K.-K. Hong, Y.-G. Kim, The critical success factors for ERP implementation: an organizational fit perspective, Inf. Manag. 40 (2002) 25-40. doi:10.1016/S0378-7206(01)00134-3.

[61] T. de Bruin, M. Rosemann, Using the delphi technique to identify BPM capability areas, Proc. 18th Aust. Conf. Inf. Syst. (ACIS 2007). 42 (2007) 643-653.

[62] J. Lee, D. Lee, S. Kang, An overview of the business process maturity model (BPMM), in: K.C. et al. Chang (Ed.), Adv. Web Netw. Technol. Inf. Manag. Lect. Notes Comput. Sci., Springer, Berlin Heidelberg, 2007: pp. 384-395. doi:10.1007/978-3-540-72909-9_42.

[63] G. O'Regan, Capability Maturity Model Integration, in: Concise Guid. to Softw. Eng., Springer International Publishing, 2017: pp. 255-277. doi:10.1007/978-3-319-57750-0_16.

[64] JoAnn Hackos, Information Process Maturity Model, in: Prof. Commun. Conf. (ProComm), 2017 IEEE Int., IEEE, Madison, WI, USA, 2017: pp. 1-7. doi:10.1109/IPCC.2017.8013946.

[65] J.-F. Tendron, The Knowledge Maturity Model, in: Trends Enterp. Knowl. Manag., ISTE, London, UK, 2006: pp. 181-195. doi:10.1002/9780470612132.ch10.

[66] K.C. Wang, J.M. Gao, Z.Y. Gao, J.Q. Liu, Information quality maturity model, Comput. Integr. Manuf. Syst. 13 (2007) 282-286. http://findit.dtu.dk/en/catalog/143696813 (accessed October 19, 2017).

[67] L. Fernando, R. Molinaro, Maturity Model for IT Enterprise Architecture, in: Proc. 5th Iber. Conf. Inf. Syst. Technol. (CISTI ), 2010: pp. 1-6.

[68] P. Antoniades, SOA Maturity Model, Springer International Publishing, Cham, 2014. doi:10.1007/978-3-319-02453-0.

[69] Strategy Management Group, The Strategic Management Maturity Model الاستراتيجية الإدارة نضج نموذج, Balanc. Scorec. Inst. (2010).

[70] M. Niknam, P. Bonnal, J. Ovtcharova, Configuration management maturity in scientific facilities, Int. J. Adv. Robot. Syst. 10 (2013) 1-14. doi:10.5772/56853.

[71] J. Tiihonen, T. Soininen, T. Männistö, R. Sulonen, State-of-the-practice in product configuration - a survey of 10 cases in the Finnish industry, Knowl. Intensive CAD. (1996) 95114. doi:10.1.1.55.1960.

[72] R. Baskerville, What design science is not, Eur. J. Inf. Syst. 17 (2008) 441-443. doi:10.1057/ejis.2008.45.

[73] J. Becker, R. Knackstedt, J. Pöppelbuß, Developing Maturity Models for IT Management - A Procedure Model and its Application, Bus. Inf. Syst. Eng. . 1 (2009) 213-222. doi:10.1007/s12599-009-0044-5.

[74] A.A. Neff, F. Hamel, T.P. Herz, F. Uebernickel, W. Brenner, J. Vom Brocke, Developing a maturity model for service systems in heavy equipment manufacturing enterprises, Inf. Manag. 51 (2014) 895-911. doi:10.1016/j.im.2014.05.001.

[75] R. Wendler, The maturity of maturity model research: A systematic mapping study, Inf. Softw. Technol. 54 (2012) 1317-1339. doi:10.1016/j.infsof.2012.07.007.

[76] A.R. Hevner, S.T. March, J. Park, S. Ram, Design science in Information Systems research, MIS Q. 28 (2004) 75-105.

http://web.b.ebscohost.com. proxy.findit.dtu.dk/ehost/pdfviewer/pdfviewer?vid=1\&sid=66b 
1ce93-2ba3-4633-83df-f85aeee05508\%40sessionmgr104 (accessed February 5, 2018).

[77] S. Gregor, The nature of theory in information systems, MIS Q. 30 (2006) 611-642. http://web.b.ebscohost.com.proxy.findit.dtu.dk/ehost/pdfviewer/pdfviewer?vid=1\&sid=fd3b 6cc6-ed38-4361-b46b-6a4ed8c51736\%40sessionmgr101 (accessed February 5, 2018).

[78] P. Fraser, J. Moultrie, M. Gregory, The use of maturity models/grids as a tool in assessing product development capability, in: IEEE Int. Eng. Manag. Conf., IEEE, Cambridge, UK, 2002: pp. 244-249. doi:10.1109/IEMC.2002.1038431.

[79] C. Voss, N. Tsikriktsis, M. Frohlich, Case research in operations management, Int. J. Oper. Prod. Manag. 22 (2002) 195-219. doi:10.1108/01443570210414329.

[80] H. ElMaraghy, G. Schuh, W. ElMaraghy, F. Piller, P. Schönsleben, M. Tseng, A. Bernard, Product variety management, CIRP Ann. - Manuf. Technol. 62 (2013) 629-652. doi:10.1016/j.cirp.2013.05.007.

[81] N. Tuomikangas, R. Kaipia, A coordination framework for sales and operations planning (S\&OP)_Synthesis from the literature, Intern. J. Prod. Econ. 154 (2014) 243-262. doi:10.1016/j.ijpe.2014.04.026.

[82] G. Cugola, L. Lavazza, V. Nart, S. Manca, M.R. Pagone, An experience in setting-up a configuration management environment, in: Proc. Eighth IEEE Int. Work. Softw. Technol. Eng. Pract. Inc. Comput. Aided Softw. Eng., IEEE Comput. Soc, 1997: pp. 251-262. doi:10.1109/STEP.1997.615501.

[83] A. Silventoinen, H.J. Pels, H. Kärkkäinen, H. Lampela, J. Okkonen, PLM maturity assessment as a tool for PLM implementation process, in: Int. Conf. Prod. Lifecycle Manag., Bremen, 2010: pp. 369-379.

https://www.researchgate.net/profile/Anneli_Silventoinen/publication/272497623_PLM_ma turity_assessment_as_a_tool_for_PLM_implementation_process/links/54e7143f0cf277664ff 77f65/PLM-maturity-assessment-as-a-tool-for-PLM-implementation-process.pdf (accessed February 1, 2018).

[84] B. Koomen, Set Based PLM Implementation, a Modular Approach to PLM Process Knowledge, Management and Automation, in: J. Ríos, A. Bernard, A. Bouras, S. Foufou (Eds.), Prod. Lifecycle Manag. Ind. Futur., Springer, Cham, 2017: pp. 3-12. doi:10.1007/978-3-319-729053_1.

[85] C. Wohlin, M. Höst, K. Henningsson, Empirical Research Methods in Software Engineering, LNCS. 2765 (2001) 7-23. https://link-springercom.proxy.findit.dtu.dk/content/pdf/10.1007\%2F978-3-540-45143-3_2.pdf (accessed June $28,2018)$.

[86] R.K. Yin, Case study research: design and methods, Sage Publications, Thousand Oaks, 2003.

[87] R. Sousa, C.A. Voss, Quality Management: Universal or Context Dependent?, Prod. Oper. Manag. 10 (2009) 383-404. doi:10.1111/j.1937-5956.2001.tb00083.x.

[88] C. Voss, N. Tsikriktsis, M. Frohlich, Case research in operations management, Int. J. Oper. Prod. Manag. 22 (2002) 198-219. doi:10.1108/01443570210414329.

[89] G. Stevens, Integrating the supply chain, Int. J. Phys. Distrib. Mater. Manag. 19 (1989) 3-8.

[90] K. Tan, V.R. Handfield, R. B, Supply chain management: supplier performance and firm performance, Int. J. Purch. Mater. Manag. 34 (1998) 2-9. 